Article

\title{
Poly(Ethylene Glycol)-Poly(L-Alanine)/Hyaluronic Acid Complex as a 3D Platform for Understanding Cancer Cell Migration in the Tumor Microenvironment
}

\author{
Jooyoung Sim ${ }^{1,2,+}$, Hyun Jung Lee ${ }^{2,+}$, Byeongmoon Jeong ${ }^{2, *}$ and Min Hee Park ${ }^{1, *(1)}$ \\ 1 Center for Convergence Bioceramic Materials, Korea Institute of Ceramic Engineering and Technology, \\ Cheongju 28160, Korea; jynjc1110@naver.com \\ 2 Department of Chemistry and Nanoscience, Ewha Womans University, Seoul 03760, Korea; \\ serve04@ewhain.net \\ * Correspondence: bjeong@ewha.ac.kr (B.J.); conomo0850@gmail.com (M.H.P.); Tel.: +82-2-3277-3411 (B.J.); \\ +82-43-913-1515 (M.H.P.) \\ $\dagger$ These authors contributed equally to this work.
}

check for updates

Citation: Sim, J.; Lee, H.J.; Jeong, B.; Park, M.H. Poly(Ethylene

Glycol)-Poly(L-Alanine)/Hyaluronic

Acid Complex as a 3D Platform for

Understanding Cancer Cell Migration in the Tumor Microenvironment. Polymers 2021, 13, 1042. https:// doi.org/10.3390/polym13071042

Academic Editor: Nirichan

Sanoj Rejinold

Received: 27 February 2021

Accepted: 24 March 2021

Published: 26 March 2021

Publisher's Note: MDPI stays neutral with regard to jurisdictional claims in published maps and institutional affiliations.

Copyright: (c) 2021 by the authors. Licensee MDPI, Basel, Switzerland. This article is an open access article distributed under the terms and conditions of the Creative Commons Attribution (CC BY) license (https:// creativecommons.org/licenses/by/ $4.0 /)$

\begin{abstract}
Cancer progression and migration in the tumor microenvironment are related to cell types and three-dimensional (3D) matrices. Therefore, developing biomimetic tumor models, including co-culture systems and a tunable 3D matrix, could play an essential role in understanding the cancer environment. Here, multicellular spheroids using human adipose-derived mesenchymal stem cells (hADSCs) and breast cancer cells (MDA-MB-231) within the 3D matrix were used as a tumor microenvironment (TME) mimicking platform. The amphiphilic peptide block copolymer and hyaluronic acid (HA) formed a self-assembled structure, which provides a biocompatible 3D environment for the cells. Multicellular spheroids were formed on the optimized plate and were observed as cell migration from a spheroid within a 3D matrix, such as the invasive and metastatic cancer of TME. This study suggests a new 3D platform using polymer complexes and the importance of tumor complexities, including various cell types and microenvironments.
\end{abstract}

Keywords: tumor microenvironment; 3D matrix; multicellular spheroid; polymer complex; migration

\section{Introduction}

Metastasis is responsible for about $90 \%$ of deaths from cancer [1]. Therefore, many researchers have developed in vitro tumor models of the most similar tumor microenvironment (TME) with patients to understand the tumor's mechanism. TME is a complex environment consisting of tumor cells, tumor stromal cells, immune cells, and extracellular matrix (ECM) components such as collagen and hyaluronan [2]. The cells, soluble factors, molecules, ECM, and mechanical cues of TME can influence tumor growth, invasion, metastasis, host immunity and therapeutic effect [3]. Thus, different cellular and non-cellular components of TME are essential to mimic the in vitro tumor model.

Three-dimensional (3D) cell culture models, such as multicellular spheroids, closely mimic the main features of the structure, cellular assembly, hypoxia condition, and nutrient gradients in solid tumors [4]. Spheroid models are a particularly good platform for studying the invasion and metastasis of cancer cells by hypoxic signaling from primary tumors. For this reason, the spheroid models have demonstrated their potential for the development of anticancer drug screening platforms over time.

Collagen is a critical biomaterial in 3D models of cancer cell invasion and metastasis, that can be induced by adding different cell types, ratios, and other ECM components. As many tumors express collagen I in the ECM in vivo and increase, the collagen density correlates with tumor growth and metastasis [5-7]. The collagen fiber alignment and matrix stiffness affect the 3D cell migration of invasive cancer cells that play a role in tumor progression [8]. We previously reported biomimetic long range fibrous orientation by ionic 
interactions between (+)-charged amphiphilic peptide block copolymer and (-)-charged hyaluronic acid (HA) to mimic bundles of the nanofibrous structures in the ECM [9]. Beside, $\mathrm{HA}$, as an ECM component that is similar to collagen, is a material that interacts with the transmembrane receptor $\mathrm{CD} 44$, which promotes cell adhesion and aggregation, and is used as a scaffold to induce cell assembly and to stimulate cancer cell migration and invasion $[10,11]$. Thus, this biomimetic 3D culture system with a nanofibrous structure can be used as a 3D scaffold to induce cancer cell migration to emulate TME, instead of the commercially available collagen and Matrigel systems.

Poly(ethylene glycol) (PEG)-polypeptides provide an amphiphilic character that can be induced and self-assembled into micelles, vesicles and nanofibers by controlling the molecular weight of the PEG and polypeptide. In addition, polypeptide accords diversity, including stereochemistry, hydrophilicity/hydrophobicity, a specific secondary structure such as a-helix, b-sheet and random coil [12-16]. Thermogels, such as PEG-polypeptide hydrogels, provide the biomimetic and cytocompatible 3D environment for the encapsulation of cells. They show the sol-to-gel transition by controlling temperature, then supply 3D space, high water content, and specific stiffness for the proliferation and differentiation of encapsulated cells [17-19].

In this study, we investigated the novel biomimetic 3D platform, consisting of a multicellular spheroid and PEG-poly(L-alanine) system which contained HA, mimicking the metastasis in TME of breast cancer for regulating cell migration. The polymer complex, through ionic interaction between amphiphilic polypeptide block copolymer and HA, was investigated to identify its possibility as a 3D matrix. Additionally, cell behavior from the multicellular spheroid embedded in the polymer complex was monitored as having a potential for mimicking the migration and invasion of cancer cells. A PEG-polyalanine-HA conjugated system (PHA) was used to provide a biocompatible 3D environment and cell adhesion site, an important parameter in TME, for inducing the cell migration [20].

\section{Materials and Methods}

\subsection{Materials}

Anhydrous $\mathrm{N}, \mathrm{N}$-dimethylformaide (Sigma-Aldrich, St. Louis, MO, USA), N-carboxy anhydrides of L-alanine (Onsolution, Seoul, Korea), $\alpha$-amino- $\omega$-methoxy-poly(ethylene glycol)s (PEG) (Mn = 2000 Da) (Pharmicell, Seoul, Korea), Diethyl ether (Daejung, Siheung, Korea), and Deuterium oxide $\left(\mathrm{D}_{2} \mathrm{O}\right)$, Trifluoroacetic acid-d ( $\left.\mathrm{CF}_{3} \mathrm{COOD}\right)$ (Sigma-Aldrich, USA) were purchased and used as received. Toluene (Daejung, Korea) was dehydrated by sodium. Chloroform (Daejung, Korea) was dried over magnesium sulfate. Sodium Hyaluronate (HA) $(\mathrm{Mn}=14,800 \mathrm{Da})$ was purchased from Lifecore biomedical (Chaska, MN, USA). Human adipose-derived mesenchymal stem cells (hADSCs) and breast cancer cells (MDA-MB-231) were received from Cefobio (Seoul, Korea) and Korean Cell Line Bank (Seoul, Korea), respectively. RPMI-1640, fetal bovine serum (FBS) and penicillin/streptomycin (PS) were purchased from Hyclone (South Logan, UT, USA). 0.25\% trypsin, 2.21mM EDTA, 1X sodium was purchased from Corning (Corning, NY, USA). 3(4,5-Dimethylthiazol-2-yl)-2,5-Diphenyltetrazolium Bromide (MTT) and live/dead viability cytotoxicity kit were purchased from Invitrogen (Carlsbad, CA, USA).

\subsection{Preparation of the mPEG-PA, HA and mPEG-PA/HA Complex Aqueous Solutions}

The mPEG-PA $(\mathrm{P})$ was synthesized by the ring-opening polymerization of the $\mathrm{N}$ carboxy anhydrides of L-alanine, where $\alpha$-amino- $\omega$-methoxy-poly(ethylene glycol)s (PEG) was used as an initiator. The $\alpha$-amino- $\omega$-methoxy-PEG was dissolved in anhydrous toluene and the residual water was removed by azeotropic distillation. Anhydrous chloroform $/ \mathrm{N}, \mathrm{N}$-dimethylformamide $(5 / 1 \mathrm{v} / \mathrm{v})$ and $\mathrm{N}$-carboxy anhydrides of L-alanine were added to the reaction mixtures. The polymerization was carried out at $40{ }^{\circ} \mathrm{C}$ for $24 \mathrm{~h}$ under anhydrous nitrogen conditions. The polymer was purified by fractional precipitation by diethyl ether, and then the residual solvent was evaporated under vacuum. The polymer was dialyzed in water using a membrane (MWCO 2000) and freeze-dried. The final yield 
was about $60 \%$. P and HA were used by dissolving in distilled water (DW) overnight at $12.0 \mathrm{wt} . \%$ and $1.0 \mathrm{wt} . \%$, respectively. mPEG-PA/HA complex (PHA) was prepared by mixing $\mathrm{P}$ and $\mathrm{HA}$ in DW to a final concentration of $12.0 \mathrm{wt} . \%$ and $1.0 \mathrm{wt} . \%$, respectively.

\subsection{H-NMR and 2-Dimesional NMR Spectroscopy}

The NMR spectroscopy (300 MHz FT-NMR Spectrometer; Varian, MA, U.S.A.) was studied to define the molecular weight of the polymer and the correlation between $\mathrm{P}$ (12.0 wt.\%) and $\mathrm{HA}(1.0 \mathrm{wt} . \%) .{ }^{1} \mathrm{H}-\mathrm{NMR}$ spectrum of $\mathrm{P}$ was acquired at $25{ }^{\circ} \mathrm{C}$ in $\mathrm{D}_{2} \mathrm{O}$ and in $\mathrm{CF}_{3} \mathrm{COOD}$, respectively. To gain further information about the interaction between $\mathrm{P}$ and $\mathrm{HA}$, homonuclear 2-dimensional NMR spectrum was measured in $\mathrm{D}_{2} \mathrm{O}$ at $25^{\circ} \mathrm{C}$.

\subsection{Fourier Transform Infrared Spectroscopy (FTIR)}

Fourier transform infrared spectra (FTIR) were obtained in a wavenumber range from 4000 to 450 across six scans with a 0.15 resolution (FTIR spectrophotometer, Frontier, PerkinElmer). The P (12.0 wt.\%) was prepared in gel state and freeze-dried to investigate at room temperature.

\subsection{Dynamic Mechanical Analysis}

The modulus of the $\mathrm{P}$ was investigated by strain-controlled rheometer, Anton Paar MCR 302 (Anton Paar GmbH, Graz, Austria) as a function of the temperature at 4-37 ${ }^{\circ} \mathrm{C}$. The sample, which was in a fluidic state at $4{ }^{\circ} \mathrm{C}$, was loaded between the parallel plates with a diameter of $25 \mathrm{~mm}$ and a gap of $0.5 \mathrm{~mm}$. After loading the sample, the temperature was maintained at $4{ }^{\circ} \mathrm{C}$ for $10 \mathrm{~min}$ and raised to $37^{\circ} \mathrm{C}$ at a heating rate of $2{ }^{\circ} \mathrm{C} / \mathrm{min}$ and then maintained at $37^{\circ} \mathrm{C}$ for $10 \mathrm{~min}$. The experiment proceeded under a controlled frequency $(1.0 \mathrm{rad} / \mathrm{s})$ and $5 \%$ strain.

\subsection{Dynamic Light Scattering(DLS) for Zeta-Potential}

Zeta potentials of the P, HA, and PHA suspended in DW (1.0 wt\%) were studied using a Zetasizer instrument (Zetasizer, ELSZ-2000, Otuska, Osaka, Japan).

\subsection{Circular Dichroism (CD) Spectroscopy}

Circular dichroism (CD) spectroscopy (CD-ORD Spectropolarimeter; Jasco Corporation, Japan) was measured as a function of concentration and temperature in the range of $\mathrm{P}$, $\mathrm{HA}$, and PHA aqueous solution (0.00625-0.1 wt.\%) at 5-40 ${ }^{\circ} \mathrm{C}$, respectively.

\subsection{Scanning Electron Microscopy (SEM)}

The P (12.0 wt.\%), HA (1.0 wt.\%), and PHA were quenched with liquid nitrogen at $-196{ }^{\circ} \mathrm{C}$ and lyophilized, respectively. Scanning electron microscope (SEM) images were obtained by the SEM instrument (EM-30, COXEM, Daejeon, Korea). The sample was cross sectioned to obtain an SEM image.

\subsection{Cell Culture}

hADSCs and MDA-MB-231 were cultured in DMEM and RPMI-1640 cell culture medium containing $10 \%$ FBS and $1 \%$ PS, respectively. Cells were maintained in a humidified incubator at $37^{\circ} \mathrm{C}$ with $5 \% \mathrm{CO}_{2}$.

\subsection{MTT Assay}

The MTT assay was performed to investigate the cytotoxicity of P, HA, and PHA on breast cancer cells. MDA-MB-231 $\left(1 \times 10^{4}\right)$ was seeded into a 96-well plate in $200 \mu \mathrm{L}$ of cell culture medium and then incubated overnight. Cells were treated with varying concentrations (1.0-0.125 wt.\%) of P, HA, and PHA (diluted in RPMI) for $24 \mathrm{~h}$. Then, $50 \mu \mathrm{L}$ MTT solution, prepared at $5 \mathrm{mg} / \mathrm{mL}$ in RPMI, was added to each well and incubated at $37{ }^{\circ} \mathrm{C}$ with $5 \% \mathrm{CO}_{2}$ for $1 \mathrm{~h}$. Sodium dodecyl sulfate (SDS) solution (0.5\% SDS, $25 \mathrm{mM}$ $\mathrm{HCl}, 90 \%$ isopropyl alcohol) was added to ensure total solubility of formazan crystals, 
and absorbance was recorded at $570 \mathrm{~nm}$ using the microplate reader (SpectraMax ABS, Molecular devices, San Jose, CA USA).

\subsection{Live/Dead Assay}

Cell viability of MDA-MB-231 in P, HA, and PHA was observed using a live/dead viability cytotoxicity kit. MDA-MB-231 $\left(1 \times 10^{5}\right)$ were seeded in a glass-bottom culture dish with $2 \mathrm{~mL}$ of cell culture medium and then incubated overnight. Cells were treated with P, HA, and PHA ( $0.5 \mathrm{wt}$.\% in cell culture medium) for $24 \mathrm{~h}$. After 2 times of phosphatebuffered saline (PBS) washing, cells were incubated at room temperature for $30 \mathrm{~min}$ in a solution of $4 \mathrm{mM}$ ethidium homodimer-1 (EthD-1) and $2 \mathrm{mM}$ calcein AM with PBS. Labeled cells were then viewed under a Nikon Eclipse E600 fluorescence microscope and images were merged using EZ photo software. Live cells and damaged cells were stained with calcein AM (green) and EthD-1 (red), respectively.

\subsection{Cell Culture}

The self-assembly of multicellular spheroids containing hADSCs and MDA-MB-231 were used to investigate cell behavior in the 3D matrix as a TME. hADSCs (A) and hADSCs/MDA-MB-231 (AM, 1:1 ratio) suspensions were seeded on an agarose-coated plate with $1 \times 10^{4}$ cells/well. The agarose coated-plate was prepared by loading agarose solution ( $2 \%$ in PBS) in a 96-well plate and used after autoclave sterilization. The hADSC growth medium (Cefobio, Korea) was supplemented and cultured for $24 \mathrm{~h}$ in an incubator at $37^{\circ} \mathrm{C}$ with $5 \% \mathrm{CO}_{2}$. After embedding the $\mathrm{A}$ and $\mathrm{AM}$ in $\mathrm{P}$ and PHA aqueous solution on a 96-well plate, the plate was incubated at $37^{\circ} \mathrm{C}$ with $5 \% \mathrm{CO}_{2}$ to induce gelation of $\mathrm{P}$ (12.0 wt.\%) and PHA. mPEG-PA/HA complex (PHA) was prepared by mixing P and HA in medium to a final concentration of $12.0 \mathrm{wt} . \%$ and $1.0 \mathrm{wt} . \%$, respectively. Cell behavior of A and AM spheroids were observed at 0, 6, 12, and $24 \mathrm{~h}$ using an Axio Vert.A1 inverted microscope (Zeiss, Oberkochen, Germany).

\section{Results and Discussion}

\subsection{Preparation of Thermosensitive Poly(L-Alanine) Hydrogel}

The mPEG-PA (P) was synthesized by ring-opening polymerization of $\mathrm{N}$-carboxy anhydrides of L-alanine in the presence of the $\alpha$-amino- $\omega$-methoxy-poly(ethylene glycol)s (PEG) $[14,21]$. The peaks of ${ }^{1} \mathrm{H}-\mathrm{NMR}$ spectra calculated the composition and molecular weight of $\mathrm{P}$ at 1.4-1.6 ppm (- $\mathrm{CH}_{3}$ of alanine), 3.3-3.5 ppm (-OCH $\mathrm{OCH}_{3} \mathrm{PEG}$ end group), and 3.5-4.1 ppm (- $-\mathrm{OCH}_{2} \mathrm{CH}_{2}$ - of PEG) (Figure 1a). The molecular weight of each block of $\mathrm{P}$ was $2000-860$ Daltons with the structure of (ethylene glycol) $)_{44}$-(L-alanine) ${ }_{12}$. The amide I band at $1570-1720 \mathrm{~cm}^{-1}$ in the FTIR spectra provides secondary structural information of a poly(L-alanine) [14]. A strong band at $1626 \mathrm{~cm}^{-1}$ and $1651 \mathrm{~cm}^{-1}$ of $P$ indicated that the poly(L-alanine) is formed with $\beta$-sheet and $\alpha$-helix secondary structures together (Figure 1b). The weak bands at $1695 \mathrm{~cm}^{-1}$ indicate an antiparallel- $\beta$-sheet of $\mathrm{P}$ [22]. The modulus of the $\mathrm{P}(12.0 \mathrm{wt} . \%)$ was measured while increasing the temperature by $2{ }^{\circ} \mathrm{C} / \mathrm{min}$ from $4{ }^{\circ} \mathrm{C}$ to $37^{\circ} \mathrm{C}$ and maintained at $37^{\circ} \mathrm{C}$. The modulus of the P shows the sol-to-gel transition as the temperature increased (Figure 1c). When the loss modulus $\left(\mathrm{G}^{\prime \prime}\right)$ is higher than the storage modulus $\left(\mathrm{G}^{\prime}\right)$ at $4{ }^{\circ} \mathrm{C}$, this means that the $\mathrm{P}$ is in a solution state and the opposite at $37^{\circ} \mathrm{C}$ is in a gel state [23]. The $\mathrm{G}^{\prime}$ (about 1000-1300 Pa) increased rapidly more than 10,000-fold, and the intersection at $15{ }^{\circ} \mathrm{C}$ of $\mathrm{G}^{\prime}$ and $\mathrm{G}^{\prime \prime}$ indicates that a sol-to-gel transition of the aqueous polymer solution has occurred. These results mean that the nanostructure of poly(L-alanine) of $\mathrm{P}$ leads to a change in the macroscopic properties by a self-assembled structure of the secondary structure as a function of the temperature. In addition, the P provides a 3D matrix for cell cultures where a high level of modulus is required. 

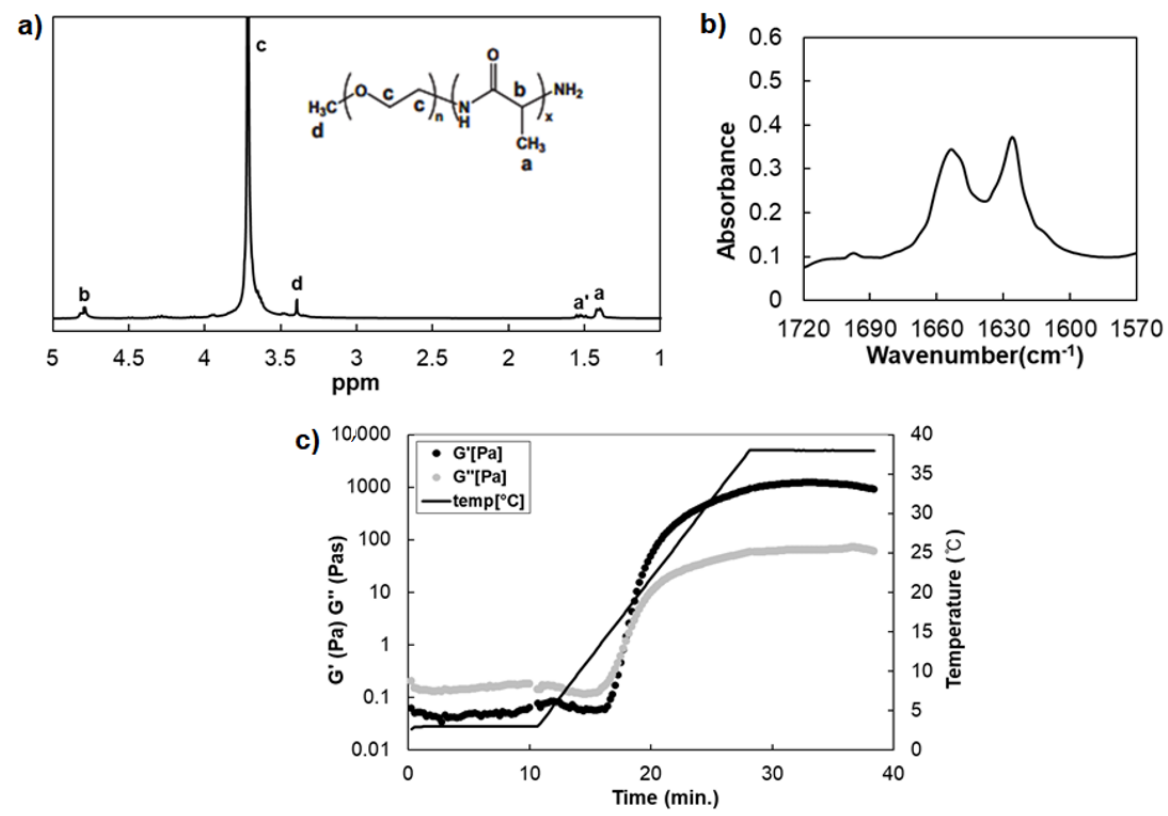

Figure 1. The characterization of mPEG-PA (P). (a) ${ }^{1} \mathrm{H}-\mathrm{NMR}$ spectra of $\mathrm{P}\left(25{ }^{\circ} \mathrm{C}\right.$ in $\left.\mathrm{CF}_{3} \mathrm{COOD}\right)$. (b) FTIR spectra of freeze-dried P. (c) Modulus of the P (12.0 wt.\% in DW) as a function of temperature $\left(4-37^{\circ} \mathrm{C}\right)$.

\subsection{Characterization of PHA Complex}

mPEG-PA/HA complex (PHA) was prepared by mixing P and HA in DW to a final concentration of $12.0 \mathrm{wt} . \%$ and $1.0 \mathrm{wt} . \%$, respectively. To identify the P and HA interactions, $\zeta$-potential, ${ }^{1} \mathrm{H}-\mathrm{NMR}, 2 \mathrm{D}-\mathrm{NMR}$, and $\mathrm{CD}$ spectra of the PHA complex were investigated. The $\zeta$-potential of $\mathrm{P}$ aqueous solution (1.0 wt. $\%$ ) was $+17.52 \mathrm{mV}$, which was reduced to $-14.47 \mathrm{mV}$ (PHA) by adding HA (Figure 2a). ${ }^{1} \mathrm{H}-\mathrm{NMR}$ spectra of the HA, P, and PHA were investigated at $25^{\circ} \mathrm{C}$ (Figure $2 \mathrm{~b}$ ). After adding HA, the HA peak at $2.02 \mathrm{ppm}$ became broader and shifted slightly, and a new broad peak at $4.56 \mathrm{ppm}$ appeared in ${ }^{1} \mathrm{H}-\mathrm{NMR}$ spectra of PHA. The homonuclear 2D-NMR spectra of HA, P, and PHA at $25{ }^{\circ} \mathrm{C}$ were measured to assign and interpret the interactions between $\mathrm{P}$ and $\mathrm{HA}$ (Figure 2c). The black arrow in the 2D-NMR of PHA indicates the methyl/methine $\left(-\mathrm{CH}_{3} /-\mathrm{CH}-\right)$ coupling resulting from the complexation between the ammonium group of terminal alanine of $\mathrm{P}$ and the carboxylate groups of HA. These results support the chemical shift and appearance of a new peak in ${ }^{1} \mathrm{H}-\mathrm{NMR}$ spectra, and 2D-NMR indicates that the P interacted with HA by ionic complexation [9].
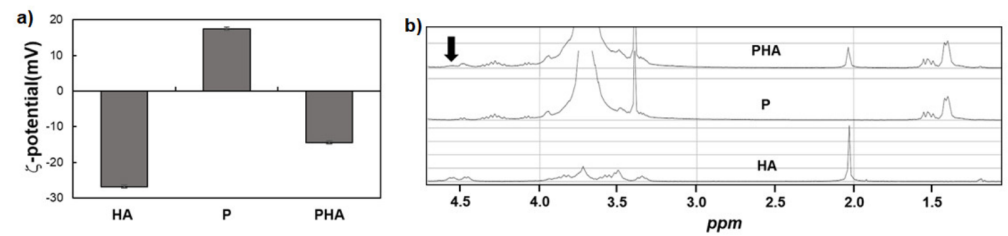

c)
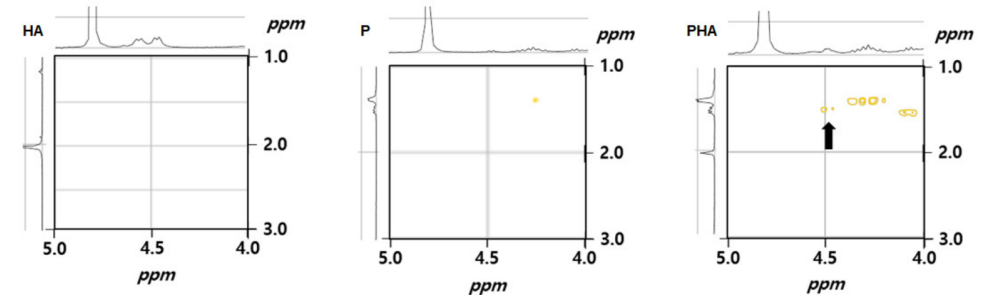

Figure 2. (a) Zeta-potential of HA, P, and PHA aqueous solutions. (1.0 wt.\%) (b) ${ }^{1} \mathrm{H}-\mathrm{NMR}$ and (c) 2D-NMR spectra of HA, $\mathrm{P}$, and PHA $\left(25^{\circ} \mathrm{C}\right.$ in $\left.\mathrm{D}_{2} \mathrm{O}\right)$. 
The poly(L-alanine), including $\alpha$-helix, $\beta$-sheet, and random coil conformations, have their characteristic chiroptical properties in CD spectra [24,25]. The CD spectrum of the $\alpha$-helix structures consists of a positive peak around 190-195 $\mathrm{nm}$ and two negative peaks at $205-210 \mathrm{~nm}$ and $215-225 \mathrm{~nm}$. $\beta$-sheet structures show a positive peak around 192-200 nm and a negative peak at $210-220 \mathrm{~nm}$. Random coil conformation shows a negative peak at 195-200 nm and a small positive peak at 215-220 nm [10]. The CD spectrum of polysaccharides is related to the molecular structure and conformation. In Figure 3a, the $210 \mathrm{~nm}$ band of HA could be attributed to the $n-\pi^{*}[26,27]$. The CD peak of the P and PHA shows the $\beta$-sheet structure predominantly at $25^{\circ} \mathrm{C}$. However, the secondary structure of $\mathrm{P}$ changed from $\beta$-sheet to $\alpha$-helix as the temperature increased (Figure 3c). In PHA, the $\beta$-sheet structure tends to dominate regardless of the temperature (Figure $3 \mathrm{~d}$ ). In addition, we found interesting results in which the changes in the CD patterns of $\mathrm{P}$ and PHA differ according to the temperature change. The $\mathrm{CD}$ values of $\mathrm{P}$ decreased while the temperature increased from $5{ }^{\circ} \mathrm{C}$ to $30^{\circ} \mathrm{C}$, and then increased with increasing temperature from $30{ }^{\circ} \mathrm{C}$ to $40^{\circ} \mathrm{C}$ (Figure 3c). PHA, on the other hand, shows an opposite pattern; the $\mathrm{CD}$ value of PHA is increased when the temperature increased from $5{ }^{\circ} \mathrm{C}$ to $30^{\circ} \mathrm{C}$ but there was a decreased peak when changing the temperature from $30^{\circ} \mathrm{C}$ to $40^{\circ} \mathrm{C}$ (Figure $3 \mathrm{~d}$ ). The $\mathrm{CD}$ values of HA showed no significant changes (Figure $3 \mathrm{~b}$ ). This trend is caused by a change in the secondary structure of $\mathrm{P}$, a poly(L-alanine) polymer, through secondary structural change due to the attraction between P and HA. These results support that PHA has unique physical and chemical properties due to the interaction of $\mathrm{P}$ and HA [9].
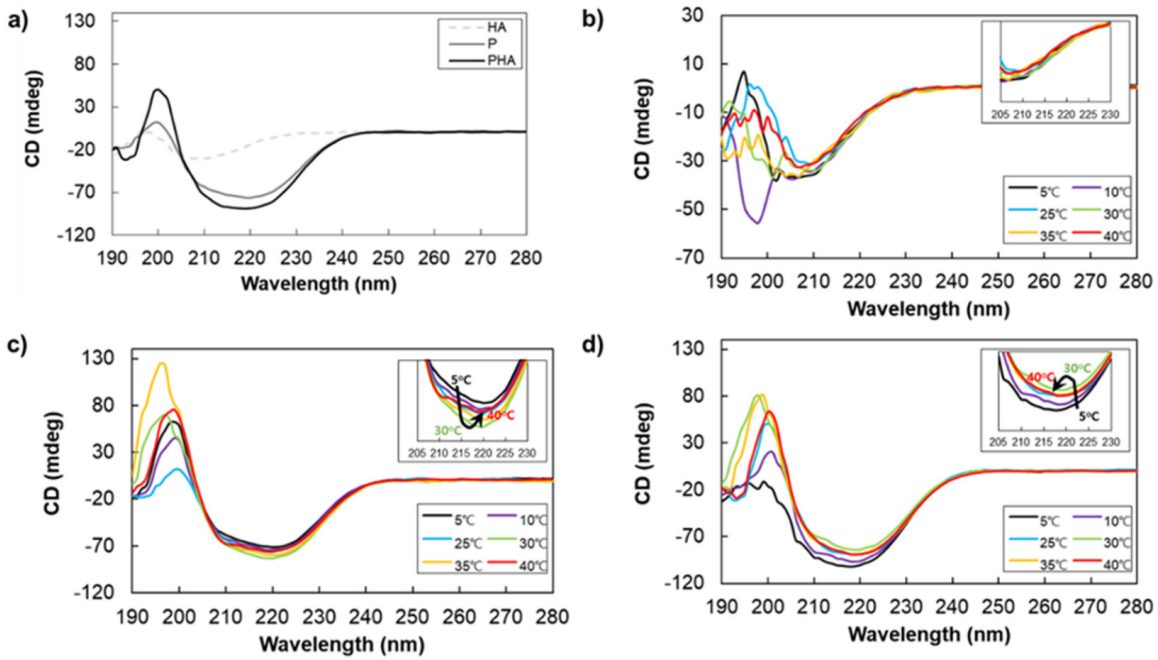

Figure 3. (a) The mean residue ellipticity of HA, P, and PHA aqueous solution $(0.0125 \mathrm{wt} . \%)$ at $25^{\circ} \mathrm{C}$ and CD spectra of (b) HA, (c) P, and (d) PHA according to temperature from $5{ }^{\circ} \mathrm{C}$ to $40{ }^{\circ} \mathrm{C}$.

\subsection{Fabrication of Tumor Microenvironment Mimicking the 3D Matrix}

The SEM examined the porous morphology of the freeze-dried HA (1.0 wt. \% in DW), P (12.0 wt.\% in DW), and PHA (12.0 wt.\% in DW) to understand the 3D structure of hydrogel. Although the internal structure/morphology of the hydrogel after freeze-drying may differ from the natural state of the swollen hydrogel, it is still helpful to understand the details of the hydrogel 3D internal microstructure [28]. As shown in Figure 4, the PHA, compared with $\mathrm{P}$, has a smaller pore size and a more compact sponge shape. This result confirmed that the structure of the hydrogel became denser with HA. This PHA structure can mimic the ECM of cancer cells, can make dense cellular aggregate in the normal cells, and promote cell migration and metastasis [29]. 

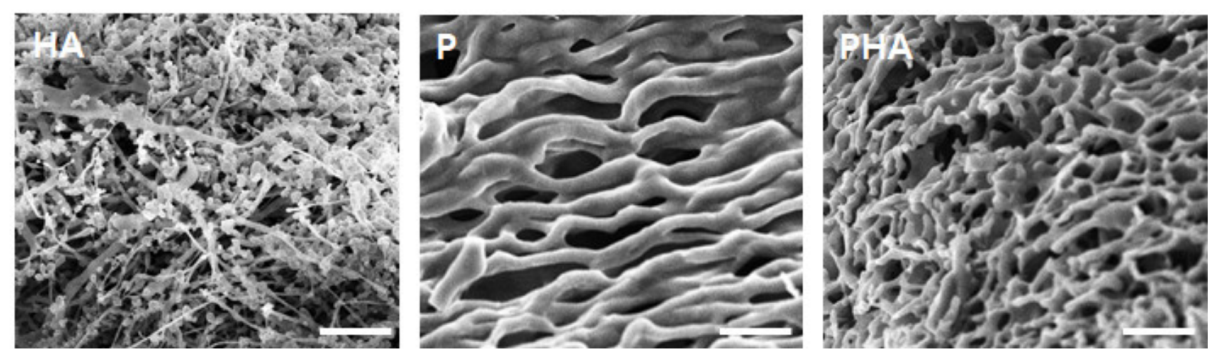

Figure 4. SEM images of freeze-dried HA (1.0 wt.\%), P (12.0 wt.\%), and PHA (12.0 wt.\%) in DW. The scale bars are $50 \mu \mathrm{m}$.

\subsection{Cell Viability}

MDA-MB-231, the breast cancer cell, was used to investigate cell cytotoxicity for HA, $\mathrm{P}$ and PHA. As shown in Figure 5a, HA, P, and PHA showed a cell viability of more than $80 \%$ at concentrations from $0.125 \mathrm{wt} \%$ to $1.0 \mathrm{wt} \%$ when compared to the non-treated group $(\mathrm{CON})$. This indicates that HA, P and PHA can be used with the cell as the biocompatible material for mimicking the tissue microenvironment. This result was also confirmed by Live/Dead assay, using fluorescence microscopy to show that the cells are alive within HA, $\mathrm{P}$, and PHA, where live and dead cells have appeared as green and red colors, respectively (Figure 5b).

a)

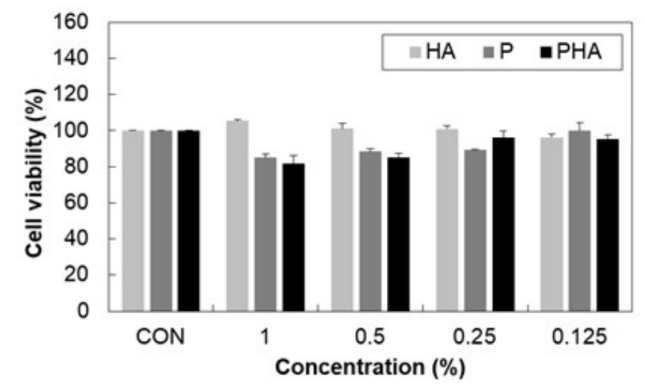

b)

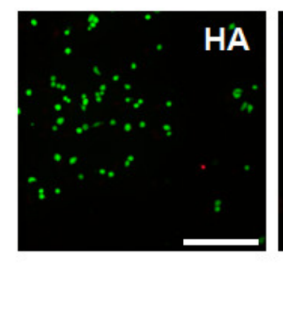

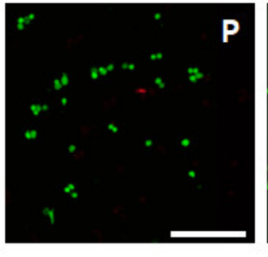

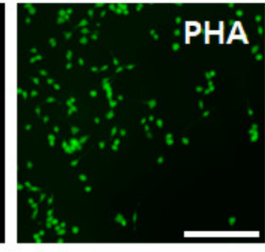

Figure 5. Cell viability of MDA-MB-231. (a) The MTT assay $(n=3)$ and (b) Live/Dead assay. The non-treated group was used as the control. Fluorescence microscopy images of MDA-MB-231 were obtained after 1 day of treatment with HA (0.042 wt.\%), P (0.5 wt.\%), and PHA (0.5 wt.\%). The cells are stained using a Live (green)/Dead (red) kit, and the image showed green and red as live and dead cells, respectively. The scale bar is $200 \mu \mathrm{m}$.

\subsection{Cell Behavior in 3D Matrix}

The cancer research has been developed in vitro 3D models such as the multicellular tumor spheroid model (MCTS) [30-33] to mimic the tumor architectural features in biological processes. In this study, we engineered 3D tumor models using the cancer cell spheroid (AM), including MDA-MB-231 and hADSCs in polymeric scaffolds. The AM was prepared by inducing the self-assembly of hADSCs/MDA-MB-231 (AM, 1:1 ratio) on the agarose coated plate. The spherical assembly was observed using an inverted microscope and SEM after seeding ( $24 \mathrm{~h}$ ) (Figure 6a). Most of the live cells indicate the green color, and the inside of spheroids showed minimal cell death by the lack of oxygen and nutrients, which indicates red color seeding (Figure 6a) [34-36]. In this study, the spheroids closely mimic the structural organization, hypoxia and nutrient gradients as the main features of solid tumors [4].

The behavior of cancer cells in the 3D matrix as mimicking the TME was examined by the area of the spheroid and cell movements from AM embedded in PHA using an inverted microscope. In PHA, the AM area was decreased by cell migration from the spheroid, indicating the black arrow (Figure $6 \mathrm{~b}, \mathrm{c}$ ). MSCs enhance breast cancer cell growth, migration and invasion through the paracrine effects [37]. MSCs' and breast cancer cells' co-culture system also regulate EMT [38]. Thus, cells in AM had been induced motility by being co-cultured with hADSCs in the 3D matrix. Figure 6d shows the spheroid's live 
and dead cells in PHA, indicating green and red color, respectively. This result means our system provides the biocompatible 3D environment to survive and migrate the cells during $48 \mathrm{~h}$.

a)

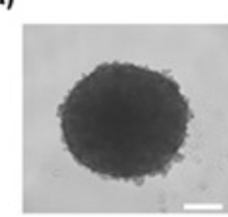

c)

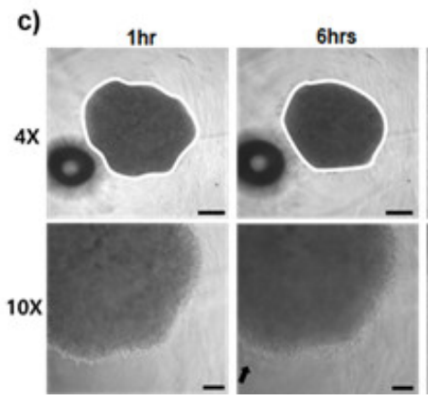

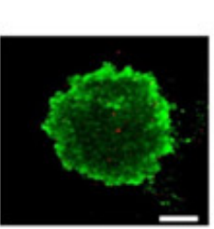

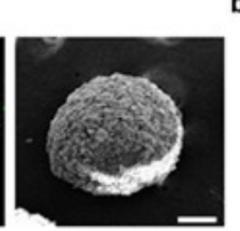

b) 120

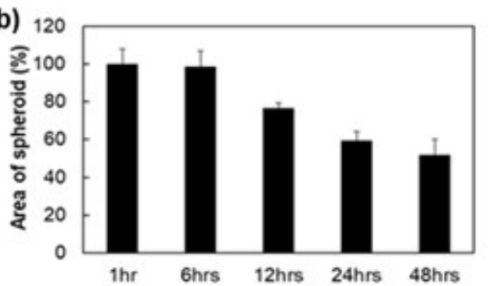

Figure 6. (a) The images of spherical assembly of AM using an inverted microscope, Live/Dead assay, and SEM. Cell behavior was measured (b) the spheroid area by Image J and (c) an inverted microscope at 1, 6, 12, 24, $48 \mathrm{~h}$. (d) Live/Dead image of the spheroid at $48 \mathrm{~h}$. The scale bar is $500 \mu \mathrm{m}$ $(4 \times)$ and $50 \mu \mathrm{m}(10 \times)$, respectively.

\section{Conclusions}

This study successfully prepared the self-assembled mPEG-PA/HA complex as a 3D matrix for mimicking the tumor microenvironment. The ion complexation between $\mathrm{mPEG}$ PA and HA was analyzed for $\zeta$-potential, ${ }^{1} \mathrm{H}-\mathrm{NMR}, 2 \mathrm{D}-\mathrm{NMR}$, and CD spectra. We also confirmed the biocompatibility of $\mathrm{P}$ and PHA. The 3D spheroids optimizing the agarosecoated plate observed spherical assembly and viability by optical microscopy, fluorescence microscopy and SEM. Finally, we induced cancer cell migration from a spheroid within a $3 \mathrm{D}$ matrix for mimicking the tumor microenvironment. In conclusion, the results of this study provide the new 3D platform with a tunable and compatible structure, and multicellular spheroids that can be used for understanding cancer invasion and metastasis in TME.

Author Contributions: Conceptualization, J.S., B.J. and M.H.P.; Methodology, J.S. and H.J.L.; Formal Analysis, J.S. and H.J.L.; Investigation, J.S., H.J.L. and M.H.P.; Data Curation, J.S. and M.H.P.; WritingOriginal Draft Preparation, J.S., H.J.L. and M.H.P.; Writing-Review and Editing, M.H.P.; Supervision, B.J. and M.H.P.; Project Administration, B.J. and M.H.P. All authors have read and agreed to the published version of the manuscript.

Funding: This work was supported by the National Research Foundation of Korea (NRF), grant funded by the Korea government (MSIT) (No. 2018R1C1B6002333).

Institutional Review Board Statement: Not applicable.

Informed Consent Statement: Not applicable.

Data Availability Statement: Data available in a publicly accessible repository.

Conflicts of Interest: The authors declare no conflict of interest. 


\section{References}

1. Fares, J.; Fares, M.Y.; Khachfe, H.H.; Salhab, H.A.; Fares, Y. Molecular principles of metastasis: A hallmark of cancer revisited. Signal Transduct. Target. Ther. 2020, 5, 1-17. [CrossRef] [PubMed]

2. Jahanban-Esfahlan, R.; Seidi, K.; Banimohamad-Shotorbani, B.; Jahanban-Esfahlan, A.; Yousefi, B. Combination of nanotechnology with vascular targeting agents for effective cancer therapy. J. Cell. Physiol. 2018, 233, 2982-2992. [CrossRef]

3. Swartz, M.A.; Iida, N.; Roberts, E.W.; Sangaletti, S.; Wong, M.H.; Yull, F.E.; Coussens, L.M.; DeClerck, Y.A. Tumor Microenvironment Complexity: Emerging Roles in Cancer Therapy. Cancer Res. 2012, 72, 2473-2480. [CrossRef]

4. Nunes, A.S.; Barros, A.S.; Costa, E.C.; Moreira, A.F.; Correia, I.J. 3D tumor spheroids as in vitro models to mimic in vivo human solid tumors resistance to therapeutic drugs. Biotechnol. Bioeng. 2019, 116, 206-226. [CrossRef] [PubMed]

5. Barsky, S.H.; Rao, C.; Grotendorst, G.R.; Liotta, L.A. Increased content of Type V Collagen in desmoplasia of human breast carcinoma. Am. J. Pathol. 1982, 108, 276.

6. Provenzano, P.P.; Inman, D.R.; Eliceiri, K.W.; Knittel, J.G.; Yan, L.; Rueden, C.T.; White, J.G.; Keely, P.J. Collagen density promotes mammary tumor initiation and progression. BMC Med. 2008, 6, 11. [CrossRef]

7. Levental, K.R.; Yu, H.; Kass, L.; Lakins, J.N.; Egeblad, M.; Erler, J.T.; Fong, S.F.; Csiszar, K.; Giaccia, A.; Weninger, W. Matrix crosslinking forces tumor progression by enhancing integrin signaling. Cell 2009, 139, 891-906. [CrossRef]

8. Riching, K.M.; Cox, B.L.; Salick, M.R.; Pehlke, C.; Riching, A.S.; Ponik, S.M.; Bass, B.R.; Crone, W.C.; Jiang, Y.; Weaver, A.M. 3D collagen alignment limits protrusions to enhance breast cancer cell persistence. Biophys. J. 2014, 107, 2546-2558. [CrossRef] [PubMed]

9. Park, M.H.; Choi, B.G.; Jeong, B. Complexation-Induced Biomimetic Long Range Fibrous Orientation in a Rigid-Flexible Block Copolymer Thermogel. Adv. Funct. Mater. 2012, 22, 5118-5125. [CrossRef]

10. Bhattacharya, D.S.; Svechkarev, D.; Souchek, J.J.; Hill, T.K.; Taylor, M.A.; Natarajan, A.; Mohs, A.M. Impact of structurally modifying hyaluronic acid on CD44 interaction. J. Mater. Chem. B 2017, 5, 8183-8192. [CrossRef]

11. Chen, C.; Zhao, S.; Karnad, A.; Freeman, J.W. The biology and role of CD44 in cancer progression: Therapeutic implications. J. Hematol. Oncol. 2018, 11, 64. [CrossRef]

12. Burkoth, T.S.; Benzinger, T.L.; Jones, D.N.; Hallenga, K.; Meredith, S.C.; Lynn, D.G. C-terminal PEG blocks the irreversible step in $\beta$-amyloid (10-35) fibrillogenesis. J. Am. Chem. Soc. 1998, 120, 7655-7656. [CrossRef]

13. Klok, H.A. Protein-inspired materials: Synthetic concepts and potential applications. Angew. Chem. Int. Ed. 2002, 41, 1509-1513. [CrossRef]

14. Choi, Y.Y.; Joo, M.K.; Sohn, Y.S.; Jeong, B. Significance of secondary structure in nanostructure formation and thermosensitivity of polypeptide block copolymers. Soft Matter 2008, 4, 2383-2387. [CrossRef]

15. Hamley, I.W.; Krysmann, M.J.; Castelletto, V.; Noirez, L. Multiple lyotropic polymorphism of a poly (ethylene glycol)-peptide conjugate in aqueous solution. Adv. Mater. 2008, 20, 4394-4397. [CrossRef]

16. Choi, Y.Y.; Jang, J.H.; Park, M.H.; Choi, B.G.; Chi, B.; Jeong, B. Block length affects secondary structure, nanoassembly and thermosensitivity of poly (ethylene glycol)-poly (L-alanine) block copolymers. J. Mater. Chem. 2010, 20, 3416-3421. [CrossRef]

17. Moon, H.J.; Park, M.H.; Joo, M.K.; Jeong, B. Temperature-responsive compounds as in situ gelling biomedical materials. Chem. Soc. Rev. 2012, 41, 4860-4883. [CrossRef]

18. Yu, L.; Ding, J. Injectable hydrogels as unique biomedical materials. Chem. Soc. Rev. 2008, 37, 1473-1481. [CrossRef]

19. Shinde, U.P.; Yeon, B.; Jeong, B. Recent progress of in situ formed gels for biomedical applications. Prog. Polym. Sci. 2013, 38, $672-701$.

20. Kamatar, A.; Gunay, G.; Acar, H. Natural and Synthetic Biomaterials for Engineering Multicellular Tumor Spheroids. Polymers 2020, 12, 2506. [CrossRef]

21. Park, M.H.; Moon, H.J.; Park, J.H.; Shinde, U.P.; Ko, D.Y.; Jeong, B. PEG-Poly(l-alanine) Thermogel As a 3D Scaffold of BoneMarrow-Derived Mesenchymal Stem Cells. Macromol. Biosci. 2015, 15, 464-472. [CrossRef]

22. Kim, E.H.; Joo, M.K.; Bahk, K.H.; Park, M.H.; Chi, B.; Lee, Y.M.; Jeong, B. Reverse thermal gelation of PAF-PLX-PAF block copolymer aqueous solution. Biomacromolecules 2009, 10, 2476-2481. [CrossRef]

23. Han, C.D.; Jhon, M.S. Correlations of the first normal stress difference with shear stress and of the storage modulus with loss modulus for homopolymers. J. Appl. Polym. Sci. 1986, 32, 3809-3840. [CrossRef]

24. Saxena, V.; Wetlaufer, D. A new basis for interpreting the circular dichroic spectra of proteins. Proc. Natl. Acad. Sci. USA 1971, 68, 969-972. [CrossRef] [PubMed]

25. Tifany, M.L.; Krimm, S. Effwct of temperature on the circular dichroism spectra of polypeptides in the extended state. Biopolym. Orig. Res. Biomol. 1972, 11, 2309-2316. [CrossRef] [PubMed]

26. Staskus, P.W.; Johnson, W.C., Jr. Conformational transition of hyaluronic acid in aqueous-organic solvent monitored by vacuum ultraviolet circular dichroism. Biochemistry 1988, 27, 1522-1527. [CrossRef]

27. Chen, H.; Qin, J.; Hu, Y. Efficient degradation of high-molecular-weight hyaluronic acid by a combination of ultrasound, hydrogen peroxide, and copper ion. Molecules 2019, 24, 617. [CrossRef]

28. Sun, X.; Zhao, X.; Zhao, L.; Li, Q.; D’Ortenzio, M.; Nguyen, B.; Xu, X.; Wen, Y. Development of a hybrid gelatin hydrogel platform for tissue engineering and protein delivery applications. J. Mater. Chem. B 2015, 3, 6368-6376. [CrossRef]

29. Poltavets, V.; Kochetkova, M.; Pitson, S.M.; Samuel, M.S. The Role of the Extracellular Matrix and Its Molecular and Cellular Regulators in Cancer Cell Plasticity. Front. Oncol. 2018, 8, 431. [CrossRef] 
30. Sutherland, R.M. Cell and environment interactions in tumor microregions: The multicell spheroid model. Science 1988, 240, 177-184. [CrossRef]

31. Vaira, V.; Fedele, G.; Pyne, S.; Fasoli, E.; Zadra, G.; Bailey, D.; Snyder, E.; Faversani, A.; Coggi, G.; Flavin, R. Preclinical model of organotypic culture for pharmacodynamic profiling of human tumors. Proc. Natl. Acad. Sci. USA 2010, 107, 8352-8356. [CrossRef]

32. Kyle, A.H.; Huxham, L.A.; Chiam, A.S.J.; Sim, D.H.; Minchinton, A.I. Direct Assessment of Drug Penetration into Tissue Using a Novel Application of Three-Dimensional Cell Culture. Cancer Res. 2004, 64, 6304-6309. [CrossRef] [PubMed]

33. Fischbach, C.; Chen, R.; Matsumoto, T.; Schmelzle, T.; Brugge, J.S.; Polverini, P.J.; Mooney, D.J. Engineering tumors with 3D scaffolds. Nat. Methods 2007, 4, 855-860. [CrossRef] [PubMed]

34. Kim, J.W.; Ho, W.J.; Wu, B.M. The Role of the 3D Environment in Hypoxia-induced Drug and Apoptosis Resistance. Anticancer Res. 2011, 31, 3237-3245.

35. Riffle, S.; Hegde, R.S. Modeling tumor cell adaptations to hypoxia in multicellular tumor spheroids. J. Exp. Clin. Cancer Res. 2017, 36, 102. [CrossRef]

36. Brüningk, S.C.; Rivens, I.; Box, C.; Oelfke, U.; Ter Haar, G. 3D tumour spheroids for the prediction of the effects of radiation and hyperthermia treatments. Sci. Rep. 2020, 10, 1653. [CrossRef] [PubMed]

37. Karnoub, A.E.; Dash, A.B.; Vo, A.P.; Sullivan, A.; Brooks, M.W.; Bell, G.W.; Richardson, A.L.; Polyak, K.; Tubo, R.; Weinberg, R.A. Mesenchymal stem cells within tumour stroma promote breast cancer metastasis. Nature 2007, 449, 557-563. [CrossRef]

38. Martin, F.; Dwyer, R.M.; Kelly, J.; Khan, S.; Murphy, J.; Curran, C.; Miller, N.; Hennessy, E.; Dockery, P.; Barry, F. Potential role of mesenchymal stem cells (MSCs) in the breast tumour microenvironment: Stimulation of epithelial to mesenchymal transition (EMT). Breast Cancer Res. Treat. 2010, 124, 317-326. [CrossRef] 